\title{
Labour Absorption in Livestock Activities in Transitional Plain Region of Rajasthan
}

\author{
A.S. Rajput ${ }^{*}$, H.K. Balai, K.C. Bairwa and L. Sharma
}

Department of Agricultural Economics and Management, Rajasthan College of Agriculture, Maharana Pratap University of Agriculture and Technology, Udaipur, Rajasthan (313001)

*Corresponding author’s Email: arjnrjpt@gmail.com

Journal of Livestock Science (ISSN online 2277-6214) 12: 292-297

Received on 4/8/21; Accepted on 25/9/21; Published on 6/10/21

doi. 10.33259/JLivestSci.2021.292-297

\begin{abstract}
In the Transitional plain regions of Rajasthan livestock activity is a complementary activity to farming and it provides much needed risk cover in case of crop failure. The present investigation was undertaken to study the labour absorption in different livestock activities in Transitional plain regions of Rajasthan. The study was conducted based on both primary and secondary data. The primary data were collected from the 200 households of 10 villages during year of the 2018-2019. The average utilization of human labour in livestock activities was found 63.27 man-days/ animal/ year in Transitional plain region. The participation of woman labour in all livestock activities was found more than man labour in all herd size group in Transitional plain region. The annual average human labour absorption was maximum in site preparation activity i.e., 48.02 hours/ animal/ year for male and 117.84 hours/ animal/ year for female, then other activities in all size of farms.
\end{abstract}

Key words: Labour absorption; livestock activity \& production; health care; standard animal unit

The results presented are part of the PhD thesis submitted by first author to the MPUAT, Udaipur. 


\section{Introduction}

India's livestock sector is one of the largest in the world. It has $56.7 \%$ of world's buffaloes, $12.5 \%$ cattle, $20.4 \%$ small ruminants, $2.4 \%$ camel, $1.4 \%$ equine, $1.5 \%$ pigs and $3.1 \%$ poultry ( $20^{\text {th }}$ Livestock census 2019$)$. The total output worth from animal was higher than the value of food grains. Animal husbandry is an integral component of Indian agriculture supporting livelihood of more than two-thirds of the rural population. Animals provide nutrient-rich food products, draught power, dung as organic manure and domestic fuel, hides \& skin, and are a regular source of cash income for rural households. They are a natural capital, which can be easily reproduced to act as a living bank with offspring as interest, and an insurance against income shocks of crop failure and natural calamities. Driven by the structural changes in agriculture and food consumption patterns, the utility of livestock has been undergoing a steady transformation. The non-food functions of livestock are becoming weaker. Importance of livestock as source of 'draught power' has declined considerably due to mechanization of agricultural operations and declining herd size. Use of dung manure is increasingly being replaced by chemical fertilizers. On the other hand, their importance as a source of quality food has increased. Sustained income and economic growth, a fast-growing urban population, burgeoning middle income class, changing lifestyles, increasing proportion of women in workforce, improvements in transportation and storage practices and rise of supermarkets especially in cities and towns are fuelling rapid increases in consumption of animal food products.

The distribution patterns of income and employment show that small farm households hold more opportunities in livestock production. The growth in livestock sector is demand-driven, inclusive and pro-poor. Incidence of rural poverty is less in some states like Punjab, Haryana, Rajasthan, Gujarat, Jammu \& Kashmir, Himachal Pradesh and Kerala where livestock accounts for a sizeable share of agricultural income as well as employment. Empirical evidence from India as well as from many other developing countries suggests that livestock development has been an important route for the poor households to escape poverty. Livestock are important for their livelihood culture and they have limited alternative opportunities for employment. However, women have little resources to improve animal productivity, to manage risk and buy good quality animals which could respond to inputs for productivity enhancement. At the same time, poverty reduction requires paradigm shifts through which the under-privileged should be enabled to earn better and gradually grow out of subsistence system through application of appropriate technology, skills, market linkages, information and service delivery systems. The agricultural sector engages about $57 \%$ of the total working population and about $73 \%$ of the rural labour force (Soju and Meena, 2017). Livestock employed 8.8\% of the agricultural work force (All India Report, Ministry of Fisheries, Animal Husbandry and Dairying, New Delhi, 2019). Animal husbandry promotes gender equity. More than three-fourth of the labour demand in livestock production is met by women. The share of women employment in livestock sector is around $90 \%$ in Rajasthan where dairying is a prominent activity and animals are stallfed (Sundari, 2020). Since crop farming is constrained by erratic rains and limited irrigation facilities, livestock is an adjunct farm enterprise in most parts of the state. Animal husbandry comes to the rescue as a measure to alleviate the effects of frequent droughts and by providing sustainable year-round income and employment to the farmers. This sector has potential to create employment in rural areas with least investments as compared to other sectors. In the light of the potential, contribution and role of the sector in the State, the present study is based on the objective to study the labour absorption in livestock activities in transitional plain region of Rajasthan with special emphasis to investigate the herd size as well as activities wise labour absorption in livestock.

\section{Materials and methods}

The present study was based on both primary and secondary data for the analysis. Primary data were collected from the farm households by personal interview based on specially designed comprehensive schedule for the agricultural year 2018-19. The simple random sampling method was used to collect the primary data of different aspects of labour absorption. The Transitional Plain Region of Rajasthan comprises six districts namely Jhunjhunu, Jodhpur, Nagaur, Pali, Sikar and Sirohi (Directorate of Agriculture, Government of Rajasthan). Out of these, two districts viz., Jodhpur and Nagaur were selected randomly on the basis of gross cropped area for the present study. Further, two tehsils Luni and Nawa were selected from Jodhpur and Nagur district, respectively. One village from each selected tehsil was selected randomly namely Salawas and Kooni, respectively. Twenty farmers were selected randomly having at least one livestock along with farming activity according to five standard size classes i.e. marginal ( $<1 \mathrm{ha}$ ), small (1-2 ha), semi-medium (2-4 ha), medium (4-6 ha) and large ( $>6$ ha) from each village. Thus, total 40 respondents were selected from the study area. Secondary data were collected from the various administrative reports, government publications, surveys, records, articles, and official documents.

The livestock activities were classified into seven sub heads viz., feeding (harvesting and carrying of fodder, cutting and mixed into dry feed etc.), watering (drinking water and bathing), production (includes dung 
collection and milking), handling (includes control of animal at the time of artificial insemination, handle at the time of medical treatment, vaccination, at calving, care after birth etc.), healthcare (cleaning of ticks, louse, medical treatment), herding and site preparation (includes cleaning of animal floor, tie up from one place to another place, maintenance and management of animal house). In the present study only cow (local and hybrid) and buffalo animal were included and categorised into young (include very young and young animal) and mature (include mature and old animal) category. Animal from birth to below 3 years of age were considered young and three years and above were considered as mature animal.

For the estimation of labour absorption in livestock activities, animals of herd size group were categorised into three categories i.e., small, medium and large. In the small herd size number of animal were up to 4 , in medium herd size 5 to 6 and in large herd size above 7 animals were considered. Considering the differences in regional endowments of animal wealth and species, the dairy animals have been converted into Standard animal units using factors suggested by Sirohi et al. (2015) for the Northern region. The absolute number of animal was converted into exact number of animal by using Standard animal units according to adult and young stock of buffalo and cattle available with the farmer on per farms.

Number of animal per farm $=$ Animal factor $*$ Absolute no. of animal per farm

Weighted average method was used for the calculation of average number of animals per farm (Gupta and Kapoor, 1970).

Where,

$$
W A=\sum_{i=1}^{n} \frac{(W i . n i)}{N i}
$$

WA=Weighted Average,

$\mathrm{Wi}=$ Weightage of animal of $\mathrm{i}^{\text {th }}$ farm

$\mathrm{i}=$ No. of animal per farm( 1 to $\mathrm{n})$ and

$\mathrm{N}=$ Total animal in district/region

For estimation of labour absorption in livestock activities, the modify model was used (model suggested for crop production by Singh, 1996 was modify for livestock).

Per hectare labour use in the district /state will be calculated as-

Where,

$$
L_{R}=\sum_{i=1}^{n} W_{i} L_{i}
$$

$\mathrm{L}_{\mathrm{R}}=$ Per animal labour absorption in the district/region/state

$\mathrm{W}_{\mathrm{i}}=$ Proportion of animal in $\mathrm{i}^{\text {th }}$ district/state to the total animal in the district

$\mathrm{L}_{\mathrm{i}}=$ Per animal labour use in the district

$\mathrm{n}=$ Number of districts/zones

\section{Results and discussion}

\section{Labour Absorption in Livestock Activities in Transitional Plain Region}

The absorption of human labour in livestock activities in transitional plain regions of Rajasthan has been studied for small, medium and large categories of herd size for the year 2018-2019. The livestock activities were categorized into sub-heads viz., feeding, watering, production, handling, health care, herding and site preparation. The absorption of human labour in livestock activities varied from animal to animal and activity to activity in different herd size group.

During 2012-2019, the changing scenarios of domestic animal's population were presented in Table-1. The population of buffaloes and cattle were augmented at 5.53 and $4.69 \%$ during 2012 to 2019 period. However, at the same time, the population of sheep, goat and overall domestic animal were declined at 12.95, 3.81 and $-1.61 \%$ respectively, in Rajasthan (Soju and Meena,(2017) reported similar finding of growth in livestock population of cattle, buffalo and sheep during 2007-2012 periods.

Table 2 present the livestock population in transitional plain region as well as Rajasthan as a whole. Among the all district of transitional plain region, the maximum share of cattle population was found in Jodhpur (7.67 \%) district and minimum was in Sirohi (1.47 \%) district with the Rajasthan (13.94 \%) as a whole (Prabu et al., 2012).

From the latest Census data (2019), it had noticed that the buffalo population was found maximum in Nagaur $(3.98 \%)$ and minimum in Sirohi $(1.54 \%)$ districts from the total share of Rajasthan (13.70\%). In this region, due to the natural habitat (desert), climatic conditions and shortage of water, the survival and adaptation in 
arid region of buffalo was found less. The population of sheep was found maximum in Pali (9.68 \%) and minimum in Jhunjhunu (1.94 \%) while goat population was maximum in Jodhpur (7.87 \%) and minimum in sirohi (1.54 \%). Borah and Halim (2014) reported similar finding of dynamics and performance of Livestock in India.

Table 1. Livestock population status of major milch animal of Rajasthan (In million)

\begin{tabular}{|l|l|l|l|l|}
\hline Sr. No. & \multicolumn{1}{|c|}{ Animal } & $\mathbf{2 0 1 2}$ & \multicolumn{1}{c|}{$\mathbf{2 0 1 9}$} & \multicolumn{1}{c|}{ change } \\
\hline $\mathbf{1}$ & Buffalo & 13 & 13.7 & 5.53 \\
\hline $\mathbf{2}$ & Cattle & 13.3 & 13.9 & 4.60 \\
\hline $\mathbf{3}$ & Sheep & 9.1 & 7.9 & -12.95 \\
\hline $\mathbf{4}$ & Goat & 21.7 & 20.8 & -3.81 \\
\hline $\mathbf{5}$ & Rajasthan (Total) & $\mathbf{5 7 . 7}$ & $\mathbf{5 6 . 8}$ & $\mathbf{- 1 . 6 1}$ \\
\hline
\end{tabular}

Source: Livestock Census, DAHS, Rajasthan, 2019

Table 2. District wise livestock population in Transitional plain region of Rajasthan (in \%)

\begin{tabular}{|l|l|l|l|l|l|}
\hline S. N. & Districts & Cattle & Buffalo & Sheep & Goat \\
\hline 1 & Jhunjhunu & 1.93 & 2.53 & 1.94 & 2.12 \\
\hline 2 & Jodhpur & 7.67 & 2.32 & 7.84 & 7.87 \\
\hline 3 & Nagaur & 4.12 & 3.98 & 5.65 & 5.74 \\
\hline 4 & Pali & 2.59 & 2.41 & 9.68 & 3.27 \\
\hline 5 & Sikar & 2.75 & 3.57 & 2.22 & 4.42 \\
\hline 6 & Sirohi & 1.47 & 1.54 & 1.95 & 1.69 \\
\hline \multicolumn{7}{|c|}{ Rajasthan (Million) } & $13.94(100)$ & $13.70(100)$ & $7.90(100)$ & $20.84(100)$ \\
\hline \multicolumn{7}{|c|}{ Source: Livestock census Rajasthan, 2019 }
\end{tabular}

Table 3. Category wise Labour Absorption in Livestock Activities in Transitional Plain Region for the year 2018-2019.

\begin{tabular}{|c|c|c|c|c|c|c|c|c|c|c|c|c|c|c|c|c|c|c|}
\hline \multirow[t]{3}{*}{ Herd size } & \multirow{3}{*}{$\begin{array}{l}\text { Animals } \\
\text { category }\end{array}$} & \multicolumn{14}{|c|}{ Livestock activities (hours/animal/year) } & \multirow{2}{*}{\multicolumn{3}{|c|}{$\begin{array}{l}\text { Total (man- } \\
\text { days/animal/year) }\end{array}$}} \\
\hline & & \multicolumn{2}{|c|}{ Feeding } & \multicolumn{2}{|c|}{ Watering } & \multicolumn{2}{|c|}{ Production } & \multicolumn{2}{|c|}{ Handling } & \multicolumn{2}{|c|}{ Health care } & \multicolumn{2}{|c|}{ Herding } & \multicolumn{2}{|c|}{ Site Preparation } & & & \\
\hline & & $\mathrm{M}$ & W & $\mathrm{M}$ & $\mathrm{W}$ & $\mathrm{M}$ & W & $\mathrm{M}$ & $\mathrm{W}$ & $\mathrm{M}$ & W & $\mathrm{M}$ & $\mathrm{W}$ & $\mathrm{M}$ & $\mathrm{W}$ & $\mathrm{M}$ & W & Total \\
\hline \multirow{3}{*}{$\begin{array}{l}\text { Small } \\
(\leq 4 \text { animals })\end{array}$} & Young & 16.73 & 34.27 & 11.58 & 45.95 & 6.65 & 10.88 & 0.00 & 0.00 & 2.71 & 4.39 & 40.70 & 126.90 & 48.67 & 93.82 & 15.88 & 39.52 & 55.40 \\
\hline & Mature & 19.52 & 64.95 & 13.92 & 92.22 & 7.57 & 49.42 & 7.36 & 18.01 & 5.41 & 9.39 & 74.71 & 165.22 & 66.69 & 141.36 & 24.40 & 67.57 & 91.97 \\
\hline & Average & 18.65 & 55.36 & 12.31 & 77.76 & 6.94 & 37.38 & 5.06 & 12.38 & 4.57 & 7.83 & 51.33 & 138.87 & 54.30 & 108.68 & 19.14 & 54.78 & 73.92 \\
\hline \multirow{3}{*}{\begin{tabular}{|l|} 
Medium \\
(5-6 \\
animals)
\end{tabular}} & Young & 12.01 & 26.19 & 8.98 & 32.73 & 5.28 & 8.03 & 0.00 & 0.00 & 2.23 & 3.63 & 38.97 & 103.84 & 40.83 & 80.60 & 13.54 & 31.88 & 45.42 \\
\hline & Mature & 18.02 & 56.39 & 10.03 & 79.10 & 5.91 & 43.82 & 7.16 & 18.63 & 4.70 & 8.20 & 47.89 & 125.56 & 52.41 & 106.31 & 18.27 & 54.75 & 73.02 \\
\hline & Average & 15.62 & 44.31 & 9.61 & 60.55 & 5.66 & 29.50 & 4.29 & 11.18 & 3.72 & 6.37 & 42.54 & 112.53 & 45.46 & 90.88 & 15.86 & 44.42 & 60.28 \\
\hline \multirow{3}{*}{$\begin{array}{l}\text { Large } \\
(\geq 7 \text { animals })\end{array}$} & Young & 16.81 & 27.66 & 9.76 & 37.60 & 6.39 & 8.35 & 0.00 & 0.00 & 3.23 & 4.26 & 31.85 & 82.99 & 36.20 & 61.92 & 13.03 & 27.85 & 40.88 \\
\hline & Mature & 19.34 & 47.10 & 17.49 & 61.43 & 11.36 & 37.22 & 9.69 & 18.55 & 4.40 & 6.64 & 56.71 & 150.89 & 61.86 & 114.08 & 22.61 & 54.49 & 77.10 \\
\hline & Average & 17.82 & 40.29 & 13.95 & 53.09 & 10.54 & 27.11 & 6.30 & 12.05 & 3.88 & 5.81 & 40.55 & 106.76 & 46.23 & 80.18 & 17.41 & 40.66 & 58.07 \\
\hline \multicolumn{2}{|c|}{ Annual Average } & 17.22 & 45.99 & 11.86 & 62.74 & 7.61 & 30.86 & 5.20 & 11.81 & 4.01 & 6.58 & 44.29 & 117.84 & 48.02 & 92.11 & 17.28 & 45.99 & 63.27 \\
\hline
\end{tabular}

Category wise Labour absorption in livestock activities in transitional plain region are revealed in Table 3. The annual per animal per year total human labour absorption in all livestock activities was 63.27 man-days, out of which man labour and woman labour contributes 17.28 man-days and 45.99 man-days, respectively. The annual average utilization of man labour was the highest in site preparation (48.02 hours/animal/year) followed by herding (44.29 hours/animal/year) and feeding (17.22 hours/animal/year) while the lowest in health care (4.01 hours/animal/year) among all livestock activities. In case of woman labour it was the highest in herding (117.84 hours/animal/year) followed by site preparation (92.11 hours/animal/year), watering (62.74 hours/animal/year) and feeding (45.99 hours/animal/year) and the lowest in health care (6.58 hours/animal/year). In this area, there was a problem of water scarcity and scarcity of green fodder, due to which farmers face problem in stall feeding the cattle. Therefore, herding activity was performed majorly in transitional plain region. Hence, the average human labour absorption was maximum in herding activity. The annual average utilization of woman labour was higher than man labour among in the all livestock activities in transitional plain region. Because most of the livestock activities such as bringing fodder from the field, chaffing the fodder, preparing feed for animals, watering, protection of animals from ticks and lice, cleaning of animals and sheds, preparing of dung cakes, milking and ghee-making are performed by farm women. Neha, 2018 and Pandit et al., 2019 was reported similar findings about the women participation in livestock activities. 
In transitional plain region, the per animal per year absorption of total human labour for small, medium and large farm category was 73.92 man-days, 60.28 man-days and 58.07 man-days, respectively. It was observed that the absorption of total human labour in livestock activities (family man and woman) was maximum on small farm and minimum on large farm. In case of small farms, numbers of animals are up to 4 while in medium and large was 5 to 6 and above 6 , respectively. Therefore, the time taken for feeding, watering, production, herding and site preparation are almost same either number of animal one or more. Due to less number of animals the absorption of human labour in livestock activities was more on small farms as compared to medium and large farms.

Table 3 depicts that the annual average absorption of man and woman labour in all livestock activities was 19.14 man-days/animal/year and 54.78 man-days/animal/year, respectively on small farms. The annual average man labour was the highest in the site preparation (54.30 hours/animal/year) followed by herding (51.33 hours/animal/year) and minimum in health care (4.57 hours/animal/year). While in case of woman labour it was maximum in herding (138.87 hours/animal/year) and minimum in health care ( 7.83 hours/animal/year). The absorption of total man and woman labour in all activities in young stock was 15.88 man-days/animal/year and 39.52 man-days/animal/year, respectively while in mature stock it was 24.40 man-days/animal/year and 67.57 mandays/animal/year, respectively on small farms. The utilization of total human labour was more in mature stock (91.97 man-days/animal/year) than young stock (55.40 man-days/animal/year). It was due to some animal specific activities which were performed only in mature stock than young stock i.e. oil cakes \& concentrates to milch cattle, milking and handling. While some activities viz., feeding, watering, dung collection, health care and site preparation were performed in both stock i.e. young and mature but the time taken was more in mature stock than young stock. Another factor is the body structure (shape and size) and feeding habits which increase the more time for mature stock.

The annual average per animal per year absorption of man and woman labour in all livestock activities was 15.86 man-days and 44.42 man-days, respectively on medium farms. The annual average absorption of man labour was the highest in the site preparation 45.46 hours/animal/year followed by herding 42.54 hours/animal/year and minimum in health care 3.72 hours/animal/year. While in case of woman labour it was maximum in herding (112.53 hours/animal/year) followed by site preparation ( 90.88 hours/animal/year), watering ( 60.55 hours/animal/year) and feeding (44.31 hours/animal/year) and minimum in health care (6.37 hours/animal/year). The per animal per year absorption of total man and woman labour in all activities in young stock was 13.54 man-days and 31.88 man-days, respectively while in mature stock it was 18.27 man-days and 54.75 man-days, respectively on medium farms. The utilization of total human labour was more in mature stock (73.02 man-days/animal/year) than young stock (45.42 man-days/animal/year) on medium farms. There was some reason for higher utilization of human labour in mature stock than young stock, as found on small farms.

The annual average absorption of man and woman labour in all livestock activities was 17.11 mandays/animal/year and 40.66 man-days/animal/year, respectively on large farms. The annual average absorption of man labour was the highest in the site preparation 46.23 hours/animal/year followed by herding 40.55 hours/animal/year and minimum in healthcare 3.88 hours/animal/year. While in case of woman labour it was maximum in herding (106.76 hours/animal/year) followed by site preparation 80.18 hours/animal/year and minimum in health care (5.81 hours/animal/year). The per animal per year absorption of total man and woman labour in all activities in young stock was 13.03 man-days and 27.85 man-days, respectively while in mature stock it was 22.61 man-days and 54.49 man-days, respectively on large farms. The utilization of total human labour was more in mature stock (77.10 man-days/animal/year) than young stock (40.88 man-days/animal/year) on large farms. It was due to some animal specific activities which was performed only in mature stock than young stock i.e. oil cakes \& concentrates to milch cattle, milking and handling (Singariya and Shekhawat, 2016) reported similar findings about female work participation more than male labour in Rajasthan. A recent study in Ethiopia revealed that over the past five years women are increasingly participating in making decisions related to sale of livestock, although the final decision remains in the hands of the household head (Kinati and Mulema, 2019).

Thus, it can be concluded that the participation of woman labour in all livestock activities was found higher than man labour in all farm size group in transitional plain region. These results were in conformity with Upadhyay and Desai (2011), Mulugeta and Amsalu (2014) and Patel et al. (2016). The annual average human labour absorption was maximum in herding activity than other activities in all size of farms and minimum in health care. As the number of animal increased from small to large farm size category the utilization of average human labour was decreased in transitional plain region.

\section{Conclusion}

The absorption of family labour was found more for mature animal than the young animal on all herd size category arid western and northern regions in the state of Rajasthan. This was due to some specific activities such as milking, feed \& fodder, handling which was more frequently carried out for mature animal than the young animal. 
The average utilization of family labour was found maximum on small herd size category while minimum was found on large herd size category. As the number of animal increased from small to large herd size category the utilization of average human labour was decreased in arid western and northern regions. In transitional plain region (Region-II), the utilization of average human labour in livestock activities was found 63.27 man-days per animal per year. Out of this, the average absorption of male and female labour was found 17.28 man-days per animal per year and 45.99 man-days per animal per year, respectively. The annual average human labour absorption was found maximum in herding activity i.e., 44.29 hours per animal per year for male and 117.84 hours per animal per year for female while minimum was found in health care i.e., 4.01 hours per animal per year for male and 6.58 hours per animal per year for female. The average utilization of family labour was found maximum on small farm (73.92 mandays per animal per year) while minimum was found on large farms (58.07 man-days per animal per year).

Acknowledgment

The facilities available at Department of Agricultural Economics and Management, Rajasthan College of Agriculture, MPUAT, Udaipur are thankfully acknowledged.

\section{References}

1) Anonymous, (2019). Livestock census Rajasthan, Government of Rajasthan.

2) Borah, M and Halim, R.A. (2014). Dynamics and Performance of Livestock and Poultry Sector in India: A Temporal Analysis. Journal of Academia Industrial Research, 3(1): 1-9.

3) GOI (2019) 20th livestock census - 2019 all India report. Ministry of fisheries, animal husbandry and dairying. New Delhi.

4) Gupta, S. C. and Kapoor, V. K. 1970. Fundamentals of Mathematical Statistics (A Modern Approach). Sultan Chand and Sons, New Delhi. pp-2.11.

5) Kinati, W. and Mulema, A.A. 2019. Gender issues in livestock production systems in Ethiopia: A literature review. Journal of Livestock Science 10: 66-80. doi.10.33259/JLivestSci.2019.66-80

6) Mulugeta, M. and Amsalu, T. (2014). Women's Role and their Decision Making in Livestock and Household Management. Journal of Agricultural Extension and Rural Development, 6(11): 347-353.

7) Neha, V. (2018). Women's Participation in Agricultural Employment with Special Reference to Uttar Pradesh and Uttarakhand in India. Economic Affairs, 63(2): 371-374.

8) Pandit, D. M., Patil, R. Aa, Kakade, A. G., Dhumal, V. S. and Shinde, S. P. (2019). Utilization of bullock animal power and constraints faced by farmers in Hingoli district. The Pharma Innovation Journal, 8(10): 40-44.

9) Prabu, M., Kumar, G.S., Pandian, A.S.S., Selvakumar, K.N. and Varathan, B.J. (2012). Dynamics of livestock population- India vis-à-vis Tamil Nadu. Tamil Nadu Journal of Veterinary and Animal Sciences, 8 (5): 266270.

10) Patel, S. J., Patel, M. D., Patel, J. H., Patel, A. S. and Gelani, R. N. (2016). Role of Women Gender in Livestock Sector: A Review. Journal of Livestock Science, 7: 92-96.

11) Singariya, M. R. and Shekhawat, H. (2016). Female Work Participation in Rajasthan: A District Level Analysis, proceeding of $35^{\text {th }}$ REA and CURAJ, PP.75-82, Flying Pen Publications, Jaipur.

12) Singh, A. 1996. Labour Absorption in Uttar Pradesh Agriculture: Structure and Determinants. Ph.D. Thesis (unpublished), Govind Ballabh Pant University of Agriculture and Technology, Pantnagar (Uttar Pradesh) India.

13) Sirohi, S., Chand, P., Sharma, D. and Saxena, R. (2015). Estimation of Bovine Equalizing Units in India: A Regional Perspective. Indian Journal of Animal Sciences, 89(9): 1009-1013.

14) Soju, S. and Meena, G. L. (2017). Dynamics of Livestock Population and Output in Rajasthan: A Temporal Analysis. Journal of Animal Research: 7 (2):345-354.

15) Sundari, S. (2020). Structural Changes and Quality of Women's Labour in India. The Indian Journal of Labour Economics, 63(1): 689-717.

16) Upadhyay, S. and Desai, C. P. (2011). Participation of Farm Women in Animal Husbandry in Anand District of Gujarat. Journal of Community Mobilization and Sustainable Development, 6(2): 117-121 